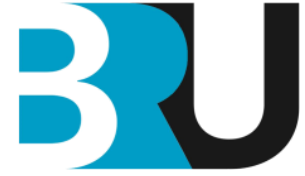

BUSINESS RESEARCH UNIT FACULTY OF BUSINESS UNIVERSITY OF MORATUWA

\title{
Unified protection for the informed decision in business transactions by legal test
}

\author{
Upeka Premaratne*
}

Department of Electronic and Telecommunication Engineering, Faculty of Engineering, University of Moratuwa, Sri Lanka

Consumers and companies alike require to make countless informed decisions in the context of commercial activities. Going beyond the trivial purchase of a substandard good or service, the informed decision is a choice made after a comprehensive evaluation of the reasonably predicted possible outcomes of each potential option. A typical example would be a consumer without expert knowledge in energy, investing in a solar power system. Under such circumstances the consumer has to be aware if there will be a benefit compared to the no action alternative which requires both information provided by the manufacturer and possible reliance on expert opinion. Venture capitalists and hedging fund managers face similar circumstances where they need to invest based upon informed decisions of the subject as well as the risks. This paper investigates the available legal remedies in both local and foreign jurisdictions for consumers and companies when deprived of an informed decision due to restriction of information, deception or perfidy. Based on this, a judicial test is formulated to allow a generalized protection of the informed decision in business transactions.

Keywords: informed decision, deceptive and misleading advertisements, misrepresentation, commercial law, legal test

\section{Introduction}

The landmark judgment of Re Ferrero Litigation (aka the Nutella Case) ${ }^{1}$ is an example of the Courts defending the consumer's right to an informed decision. In this case, the plaintiffs who were two mothers from California sued Ferrero U.S.A., Inc. for misleadingly promoting a product (Nutella) as a healthy dietary

1In re Ferrero Litigation, 768 F. Supp. 2d 1074 (S.D. Cal. 2011).

*Email: upeka@uom.lk 
option for children when it actually had potentially harmful levels of sugar. Under the established doctrine of informed consent in medical treatment and research, a patent is made aware of all potential pros and cons of a course of treatment. Similarly, a volunteer for medical research has to be fully aware about being a test subject. However, the general informed decision has little or no direct legal protection in most jurisdictions besides consumer protection laws. Often consumer protection laws themselves may have limited scope and application. For example, in Re Ferrero Litigation, the plaintiffs had to argue under the Unfair Competition Law, False Advertising Law and Consumer Legal Remedies Act of the State of California in addition to breaches of warranty.

Considering an advertisement as an invitation to treat (i.e., invitation to enter negotiations) has been a common tactic for the advertiser to rebuff liability as in Leonard v. Pepsico, Inc. (aka the Pepsi Points Case) ${ }^{2}$ where an advertisement that represented a Harrier Jet as worth 7 million points that could be earned was judged as not being a binding contract. Instead it was judged as puffery which as subsequently stated in Newcal Industries v. Ikon Office Solution ${ }^{3}$, “...no reasonable person would take literally”.

This raises the issue of competency above capacity (Leo, 1999) and whether it is fair for a judgment to simplify the issue to a "reasonable and unreasonable person" dichotomy. For example, from the essence of Re Ferrero Litigation is it fair to expect an average housewife making a purchase of a breakfast spread at a supermarket to be able to interpret the amount of sugar on a label as "harmful" like a qualified nutritionist? Both have the same capacity but different competency. Thus, both require equitable representations to make the same informed decision.

In this light the recent Food (colour coding for sugar levels) Regulations 2016 under Section 32 of the Food Act No. 26 of 1980 of Sri Lanka that requires all beverages have to be marked as low, medium and high sugar with a colour coding of red for high sugar can be considered a better representation in terms of consumer competency. Furthermore, the matter can get further complicated when an individual seeks expert advice to compensate for lack of competency. Under such circumstances, the client is also vulnerable to perfidy by the expert.

Beyond consumer affairs there are many occasions where an informed decision comes up in the context of business such as in venture capital investments where the investor is expected to be well informed about the circumstances. Therefore, in an age of increased information awareness and accessibility, a holistic approach to protecting companies and consumers alike against denial of an informed decision during a value transaction is opportune.

\subsection{Contribution}

In this paper, a holistic legal test is proposed to evaluate whether a consumer or company has been wronged based upon the need for an informed decision. This test, simplifies legal matters related to product sales, investment, insurance and fraud by using a generic definition for an informed decision and test as to whether the denial of the information necessary for the decision

2Leonard v. Pepsico, Inc., 88 F. Supp. 2d 116 (S.D.N.Y. 1999).

3 Newcal Industries v. Ikon Office Solution, 513 F.3d 1038 (9th Cir. 2008). 
would determine whether the business transaction takes place or not.

\subsection{Outline of the paper}

Section 2 defines an informed decision and investigates the factors that deprive it. The available legal remedies are summarized in Section 3. The proposed test is given in Section 4.

\section{Preliminaries}

\subsection{Definition of an informed decision}

An informed decision can be defined as "a choice made with a reasonable understanding of the potential benefits, detriments and risks involved with the outcome of each available option along with awareness of any relevant circumstances". This definition can be taken as a generalization of Article 22 of the Helsinki Declaration of 1964 which covers informed consent when volunteering for medical research with elements of Black's definition of fraud (Black 1990). This is de-contextualized generalization intended to simplify legal constructs.

\subsection{Previous work}

The requirement for an informed decision is widespread in the business world. Numerous studies focus on the requirement and benefits such as during investment of venture capital (Rosenstein, Bruno, Bygrave \& Taylor, 1993), human resource outsourcing (Greer, Youngblood \& Gray, 1999), risk management (Conforti, De Leoni, La Rosa \& Van Der Aalst, 2013), information technology related investments (Scheepers \& Scheepers, 2008) and tourism management (Fröschl \& Werthner, 1997). The use of digital technology has had a positive impact on forming an informed decision through improved access to information (Raisinghani, 2003), effective visualization of the informed decision making process (Charters, Knight, Thomas \& Munro, 2002) and formulation of business intelligence based decisions (Khan \& Quadri, 2012; Azma \& Mostafapour, 2012).

Research into the effectiveness of an informed decision focus on case studies such as small businesses (Barnes et al., 1998; Geisler, 1992), consumer spending (Norman, 2010), learning during the business cycle (Schivardi, 2003) and outsourcing of information systems (Grover \& Teng, 1993). Studies on the legal and ethical issues related to an informed decision are limited (Balotti \& Hanks Jr, 1993; Bowers, 2001; Thomas, Schermerhorn Jr \& Dienhart, 2004).

\subsection{Denial of an informed decision}

Denial of an informed decision can take three forms- restriction, deception and manipulation, and perfidy- when an expert opinion is relied upon due to lack of competency.

Restriction. Restriction is when the decision making agent is deprived of or deliberately made difficult to access the necessary information for an informed decision. The notorious small print (aka fine print) is a typical example in business where unfavourable terms of an agreement are deliberately printed 
in small text so that the consumer will not read them. An example court case is that of the Australian Federal Court case of Australian Competition and Consumer Commission v. Clarion Marketing 4 where the small print on the top of a scratch card stating it was necessary to subscribe to a mobile phone service to be eligible to win the prize was judged as unreasonable. In the Australian case of Cassidy v. Medical Benefits Fund of Australia 5 unfavourable conditions in small print that contradict the prima facie impression of the advertisement were deemed deceptive and misleading. In ACCC $v$. Boost Tel ${ }^{6}$ the prominent display of the low rate and the mention of the exceptional and highly unlikely circumstances under which the rate applies in small print was judged as unfair.

Another instance of restriction is non-disclosure or obscuring of critical information. Withholding tax refund information was the basis of Nadinic $v$. Drinkwater $^{7}$ where the plaintiff stated that she would have called for a second mortgage of a property had she been fully aware of the facts. Similarly, in Re Ferrero Litigation, the spread portrayed as a healthy food obscured the fact that it had potentially harmful levels of sugar to the extent that a person of average competence would not have been able to comprehend this fact.

The requirement of utmost good faith (uberrimae fidei) during insurance where the client is expected to disclose all necessary information on the subject matter of the insurance is also to allow the insurer to make the most informed decision on the insurance policy. In Kraft v. FTC ${ }^{8}$, the Federal Trade Commission (FTC) sued Kraft for deceptive advertising. This was based upon the claim that Kraft Singles were made out of five ounces of milk and hence, contained more calcium than similar products of competitors. The company had not mentioned the fact that $30 \%$ of calcium was lost during the manufacturing process. However, despite this non-disclosure, the court decided that objective surveys from consumers were needed to determine if the advertisements were indeed misleading.

Deception and manipulation. Deception is being untrue and when coupled with an emotion it manipulates a consumer into overriding a rational informed decision. This interplay is well investigated from a psychological standpoint (Chaudhuri, 2006; Gratch, 2000; Helion \& Pizarro, 2015; Monin, Pizarro, \& Beer, 2007). From a neurological perspective it can be simplified as an interaction between the amygdala of the brain that is hardwired for reward (Baxter \& Murray, 2002), the basal ganglia which mainly handles emotional response and the pre-frontal cortex where analysis and reasoning take place (Frank, Cohen, \& Sanfey, 2009; Satpute \& Lieberman, 2006). An example case

\footnotetext{
4Australian Competition and Consumer Commission v Clarion Marketing Pty Ltd [2009] FCA 1441

5Cassidy and Another v. Medical Benefits Fund of Australia and Another (No. 2) [2002] FCA 1097

6Australian Competition and Consumer Commission v Boost Tel Pty Limited [2010] FCA

701

7Nadinic v Drinkwater [2017] NSWCA 114 (30 May 2017)

8Kraft, Inc. v. Federal Trade Commission, 970 F.2d 311 (7th Cir. 1992).
} 
for this method is that of ACCC v. Henry Kay ${ }^{9}$ where an advertisement that appealed to the desire for an ordinary person to become a millionaire within 12 months was judged as being deceptive. The case included the element of denial as well since the relevant definitions were given in small print.

Perfidy. Perfidy in the context of business is when a degree of fiduciary trust is abused. A noteworthy case is that of Edelson v. Encore Networks ${ }^{10}$ where a venture capital firm invested in a previously bankrupt communication company based upon false sales forecasts provided under trust by the president and CEO of the company.

\section{Protective legislation}

In Sri Lanka business matters come under the purview of numerous Acts and regulations such as the Consumer Affairs Authority Act No 09 of 2003 (CAAA), the Regulation of Insurance Industry Act No. 43 of 2000 and Section 32 of the Food Act No. 26 of 1980 that allows the respective Minister to enact regulations. These sources of law have elements of the informed decision but no explicit mention. Neither Article 14A of the Constitution (as amended by the 19th Amendment) nor the Right to Information. Act, No. 12 of 2016 covers business transactions.

\subsection{The Consumer Affairs Authority Act}

The CAAA has clauses with elements that protect an informed decision by recognizing the consumer's right to information on the product. Examples include

- $\quad$ Section 8 (e) "to keep consumers informed about the quality, quantity, potency, purity, standards and price of goods and services made available for purchase", (h) "undertake studies, publish reports and provide information to the public relating to market conditions and consumer affairs" and (j) "promote consumer education with regard to good health, safety and security of consumers".

- Section 10 (1) (a) the authority may issue directions on labelling and under (4) wilful tampering with such labels is a punishable offense.

- Section 29 traders are required to maintain a notice board to inform customers of notices, directions and warnings by the authority.

- Section 30 traders must refrain from deceptive or misleading conduct or under Section 31 make false representations

When compared to other jurisdictions such as in Australia, the equivalent Australian Competition and Consumer Commission (ACCC) has litigated a number of cases related to denial of an informed decision as misleading or deceptive advertisements.

Under other jurisdictions, the UN Guidelines for Consumer Protection

9Australian Competition and Consumer Commission v Henry Kaye and National Investment Institute Pty Ltd [2004] FCA 1363

10 Edelson v., LP v. Encore Networks, Inc., Civ. No. 2: 11-5802 (KM) (D.N.Y. May 9, 2013). 
1999 recognizes the consumer's right to an informed decision under Section 3 (c) which mentions "...access of consumers to adequate information to enable them to make informed choices according to individual wishes and needs." and Section 3 (d) on "...consumer education, including education on the environmental, social and economic impacts of consumer choice". The Consumer Protection Act 1987 of the United Kingdom enacted prior to the UN guidelines only focuses on product safety under Part II and misleading prices under Part III with no mention of informed choice.

\subsection{Regulation of Insurance Industry Act}

Section 99 (1) of the Act states "Advertisements issued by insurers, insurance agents, and brokers shall not contain any information or material which is false, incorrect or is likely to mislead the public.". This is essentially though not explicitly the requirement of disclosure of the right information. Under English Law, the precedent of Carter $v$ Boehm ${ }^{11}$ that requires utmost good faith applies, protecting the right of the insurer to make an informed decision based upon all disclosed facts.

\subsection{Food (Labelling and Advertising) Regulations 2005}

Section 11 prohibits endorsement of foods by professional bodies or individuals without approval from the Chief Food Authority (CFA). Section 12 forbids making special claims for food products without approval from the CFA. Section 13 of the said regulations prohibits deceptive and misleading advertising.

\section{Proposed legal test}

From the legislation of Sri Lanka (Section 3) and Re Ferrero Litigation it becomes apparent that especially deceptive advertisements and professional misconduct are difficult to litigate due to the complexity of the legislation. In Australia the comprehensive Trade Practices Act No. 51, 1974 simplifies litigation on general trade practice including deceptive conduct (Section 52) but does not include perfidy. To simplify matters further and holistically incorporate all possible avenues under which an individual or company can be harmed, the informed decision test is proposed. It consists of the following criteria

1. Was there an intentional (or negligent) denial of necessary information to make an ${ }^{12}$ informed decision?

2. Would the transaction have taken place had the consumer (or client) been able to contemplate (with assistance if necessary) the denied information?

\subsection{Analysis}

The first criterion excludes the possibility of honest mistakes as in Beslity $v$. Manhattan Honda where a knowledgeable person attempted to exploit a mistake in an advertisement. It covers both the intention and act of denial. The 
second criterion of the test will allow cases such as Strishak v. Hewlett Packard ${ }^{13}$ to be decided consistently. In the mentioned case, the ink cartridge provided free of charge with a printer was an economy cartridge instead of the regular one. Failing to list this is unlikely to have an effect on the transaction because the main item of purchase is the printer and not the ink.

The absence of the monetary damage eliminates possible subjective decisions, offering equal protection for small purchases and large investments. The test result is consistent with the judgments of all of the cases in Section 2.3 except Kraft v. FTC. The ratio of Kraft v. FTC was based upon a hypothetical contradictory test that had it been conducted would have relied upon subjects who lacked the necessary competency and awareness of themselves being misled. When the proposed test is applied, criterion one would be satisfied because the company had not mentioned the fact that $30 \%$ of calcium was lost during the manufacturing process. A consumer concerned about ones' calcium intake would then choose the next best option in the market. This satisfies the second requirement. Hence, the test would succeed and the judgment would be in favour of the FTC.

\subsection{Illustrative example}

A customer is to choose between two quotations for solar energy systems. Due to his lack of subject knowledge he hires an expert for his opinion. Out of the two, one is for Rs. 2 million and the other for Rs. 2.5 million. The expert fails to disclose that the solar panels of the cheaper quote are of low quality and would depreciate faster, resulting in a lifetime of only five years compared to ten for the other quote. After installing the cheaper quote, the customer finds this out and sues the expert for damages. In this example both criteria of the test are satisfied. The customer was denied the necessary information about the solar panel lifetime and would have chosen the expensive system with a longer lifetime had he been aware of the undisclosed information. This test would stand, regardless of whether the expert did so out of vested interests or negligence.

\subsection{Possible consequences}

The introduction of this legal test and willingness of affected parties to sue based on it can have numerous consequences. Some foreseeable consequences include:

1. More informative labelling that would suit the cognitive abilities of a person of average competence. For example, the recent Food (Colour Coding for Sugar levels) Regulations of 2016 that requires all beverages have to be marked as low, medium and high sugar with respective colour coding of yellow, orange and red is a significant improvement over simply including sugar as an ingredient. This is due to the natural association of red with danger and the proportionality of red with the associated harm. This can be further improved by including the sugar content as a percentage of the recommended daily

13Andre Strishak and Associates, PC v. Hewlett Packard Company, 300 A.D.2d 608, 752 N.Y.S.2d 400 (App. Div. 2002). 
intake (RDI). Often, the RDI is included in terms of a serving size. Therefore, relating the RDI to the total sugar content in the container is also beneficial for a consumer of average competence. The undesirable effect of this would be the need for more space to include all of the necessary information on the package.

2. Increased accountability when offering expert advice. It may also result in experts becoming more reluctant to offer advice due to legal ramifications.

\section{Conclusion}

In this paper a versatile legal test is proposed that provides protection to a business transaction that requires an informed decision based upon the pros and cons of each eventuality. It can be applied to different situations related to sale of goods, insurance and investment. Investigation of consumer perception of such a legal test is the main future direction of this work.

\section{References}

Azma, F., \& Mostafapour, M. A. (2012). Business intelligence as a key strategy for development organizations. Procedia Technology, 1, 102-106.

Balotti, R. F., \& Hanks Jr, J. J. (1993). Rejudging the Business Judgment Rule. The business lawyer, 1337-1353.

Barnes, M., Dickinson, T., Coulton, L., Dransfield, S., Field, J., Fisher, N., ... \& Shaw, D. (1998, July). A new approach to performance measurement for small to medium enterprises. In conference proceeding Performance MeaurementTheory and Practice (Vol. 2, pp. 86-92).

Baxter, M. G., \& Murray, E. A. (2002). The amygdala and reward. Nature reviews neuroscience, 3(7), 563.

Bowers, H. M. (2001). Fairness opinions and the business judgment rule: an empirical investigation of target firms' use of fairness opinions. Nw. UL Rev., 96, 567.

Charters, S. M., Knight, C., Thomas, N., \& Munro, M. (2002, July). Visualisation for informed decision making; from code to components. In Proceedings of the 14th international conference on Software engineering and knowledge engineering (pp. 765-772). ACM.

Chaudhuri, A. (2006). Emotion and reason in consumer behavior. Routledge.

Conforti, R., De Leoni, M., La Rosa, M., \& Van Der Aalst, W. M. (2013, June). Supporting risk-informed decisions during business process execution. In International Conference on Advanced Information Systems Engineering (pp. 116-132). Springer, Berlin, Heidelberg.

Frank, M. J., Cohen, M. X., \& Sanfey, A. G. (2009). Multiple systems in decision making: A neurocomputational perspective. Current Directions in Psychological Science, 18(2), 73-77.

Fröschl, K. A., \& Werthner, H. (1997). Informed Decision Making in Tourism Management Closing the Information Circuit. In Information and Communication Technologies in Tourism 1997 (pp. 75-84). Springer, Vienna.

Geisler, E. (1992). Managing information technologies in small business: Some 
practical lessons and guidelines. Journal of General Management, 18(1), 7481.

Gratch, J. (2000, May). Modeling the interplay between emotion and decisionmaking. In Proceedings of the 9th Conference on Computer Generated Forces and Behavioral Representation (pp. 1-11).

Greer, C. R., Youngblood, S. A., \& Gray, D. A. (1999). Human resource management outsourcing: The make or buy decision. The Academy of Management Executive, 13(3), 85-96.

Grover, V., \& Teng, J. T. (1993). The decision to outsource information systems functions. Journal of Systems Management, 44(11), 34.

Helion, C., \& Pizarro, D. A. (2015). Beyond dual-processes: the interplay of reason and emotion in moral judgment. In Handbook of neuroethics (pp. 109-125). Springer Netherlands.

Black, H. C. (1990). Black's Law Dictionary, Definition of The Terms and a Phrases of American and English Jurisprudence, Ancient and Modern, St. Paul, Minnesota.

Khan, R. A., \& Quadri, S. M. K. (2012). Business intelligence: an integrated approach. Business Intelligence Journal, 5(1), 64-70.

Leo, R. J. (1999). Competency and the capacity to make treatment decisions: a primer for primary care physicians. Primary care companion to the Journal of clinical psychiatry, 1(5), 131.

Monin, B., Pizarro, D. A., \& Beer, J. S. (2007). Deciding versus reacting: Conceptions of moral judgment and the reason-affect debate. Review of General Psychology, 11(2), 99.

Norman, A. S. (2010). Importance of financial education in making informed decision on spending. Journal of economics and International Finance, 2(10), 199-207.

Raisinghani, M. S. (Ed.). (2003). Business Intelligence in the Digital Economy: Opportunities, Limitations and Risks: Opportunities, Limitations and Risks. Igi Global.

Rosenstein, J., Bruno, A. V., Bygrave, W. D., \& Taylor, N. T. (1993). The CEO, venture capitalists, and the board. Journal of business venturing, 8(2), 99113.

Satpute, A. B., \& Lieberman, M. D. (2006). Integrating automatic and controlled processes into neurocognitive models of social cognition. Brain research, 1079(1), 86-97.

Scheepers, H., \& Scheepers, R. (2008). A process-focused decision framework for analyzing the business value potential of IT investments. Information Systems Frontiers, 10(3), 321-330.

Schivardi, F. (2003). Reallocation and learning over the business cycle. European Economic Review, 47(1), 95-111.

Thomas, T., Schermerhorn Jr, J. R., \& Dienhart, J. W. (2004). Strategic leadership of ethical behavior in business. Academy of Management Perspectives, 18(2), 56-66. 